\title{
Soft Swichting DelDc Converter With Full Zvs Range And Reduced Out Put Filter For High Voltage Application
}

\author{
Vinnarasi Ponnury. $\mathrm{P}^{1}$ \\ ${ }^{I}$ (Assistant professor, Department of Electrical and Electronic Engineering ,Jeppiaar Institute of Technology \\ ,chennai)
}

\begin{abstract}
In this Project, we analyzed a switched resonant power converter for solar power applications.This circuit topology integrates a switched resonant Converter with zero-voltage switching (ZVS).Resonant converters are extensively utilized in the application of solar power generation systems. The basic requirements of resonant converters are their small size and high efficiency.A high switching frequency is required to achieve small size.To solve the problems due to the switching losses, some soft-switching approaches must be used at high switching frequencies such as Zero- voltage switching (ZVS). High frequency switching reduces the transformer size and filter size. But increase the switching losses. Soft switching is used to reduce the switching losses with help of LC component.
\end{abstract}

Keywords: DC-DC-conversion, Soft Switching, modular multilevel converters (MMCs), resonant converter, Solar energy.

\section{Introduction}

In the last few decades, various research studies have been performed to improve the switch transition to overcome this inherent problem of hard-switching in PWM converters.By solving these high voltage and current stress problems, energy conversions using resonant converters have been important in ensuring both high performance and supporting energy conservation applications in renewable energy generation systems.ZVS scheme eliminates capacitive turn-on losses and decreases the turnoff switching losses by reducing the rate of increase in voltage, reducing the overlap between the switch voltage and the switch current. However, the switching loss increases with the switching frequency, reducing the efficiency of the resonant converters. To solve this problem, some soft-switching approaches must be used at high switching frequencies. Zero voltage switching (ZVS) and zero-current switching (ZCS) techniques are two commonly used soft-switching methods.
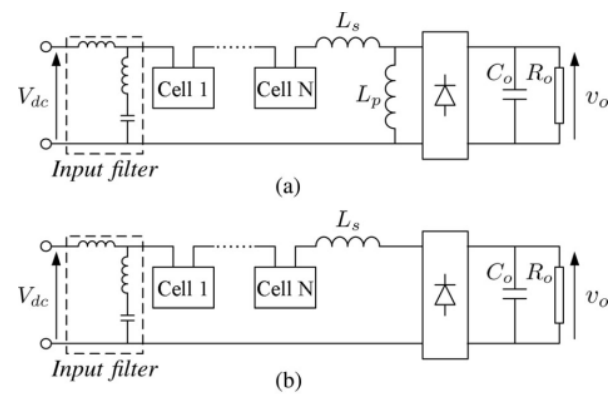

(b)

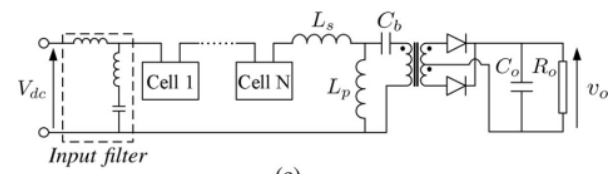

Fig. 1.High step-down ratio unidirectional dc-dc converter topologies.

(a) Transformerless converter with series-parallel resonance.

(b)Transformerlessconverter with series resonance.

(c) Transformer isolated converter.

This project proposes a dc power supply system to give high power factor and low current distortion on the rectifier side and provide stable dc voltage on the isolated $\mathrm{dc} / \mathrm{dc}$ converter side. The proposed $\mathrm{dc}$ power supply system uses a new zero-voltage switching (ZVS) strategy to get ZVS function. Besides operating at high switching frequency, all semiconductor devices operate at soft switching. A significant reduction in the conduction losses is achieved, since the circulating current for the soft-switching flows only through the auxiliary circuit and a minimum number of switching devices are involved in the circulating current path and the rectifier in the proposed dc power supply system uses a single converter instead of the conventional 
configuration composed of a four-diode front-end rectifier followed by a boost converter. An average-currentmode control is employed in proposed dc power supply system to detect the transition time and synthesize a suitable low harmonics sinusoidal waveform for the input current.

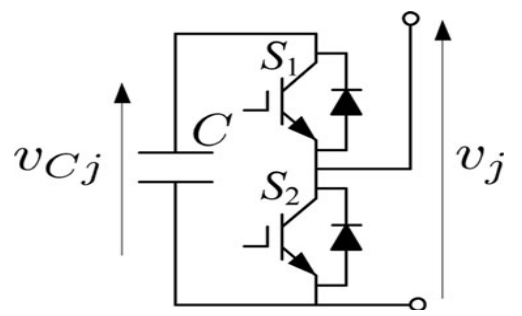

Fig. 2. Circuit configuration of a half-bridge cell.

\section{Proposed Schem}

Dc power supplies have been widely used in industrial equipments, such as dc uninterruptible power supply and telecommunications power supply, and high power factor and low input-current harmonics are mandatory performances of the dc power supplies for satisfied agency standards such as EN61000-3-2. Although the traditional passive diode rectifier/LC filter can be used to correct the power factor and these standards are also possibly satisfied, the size of low-frequency inductors and capacitors will result in the dc power supplies, which are very bulky and heavy. The passive filter approach to PFC is limited to applications where the size and weight of the converter are not major concerns. For overcoming this problem, a boost powerfactor-corrected (PFC) front-end converter followed by a transformer-isolated dc-dc converter is the most extensively employed in offline power supplies, and full-bridge transformer-isolated dc/dc converter is the most extensively applied in medium-to-high power dc/dc power conversion. For solving the problem that the boost rectifier and the full-bridge transformer-isolated $\mathrm{dc} / \mathrm{dc}$ converter must use individual soft-switching techniques to reduce their switching losses, a simple ZVS strategy is also proposed in this paper using solar power.

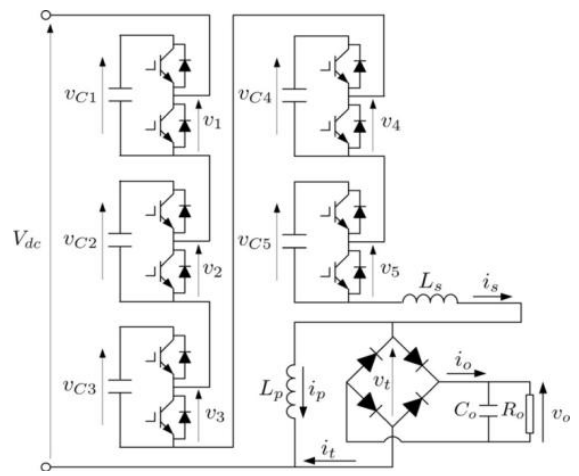

Fig.3.Five-cell step-down series-parallel resonant converter.
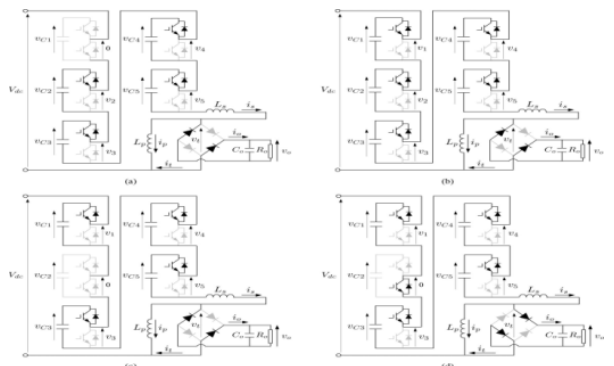

Fig. 4.Modes of operation of resonant converter

The first mode starts when the lower switch in Cell 1 is turned OFF, and the circuit enters the dead time mode of Cell $1 \mathrm{In}$ this mode 1.No current flows through cells and all the current circulates between the parallel inductor and the rectifier.After a short time, the upper switch in Cell 1 is turned ON and the circuit enters mode 2 . All the cell capacitors are in series with the inductor Ls. The input voltage of the rectifier is negative. Therefore, the input current it is negative. This mode lasts until the upper switch of Cell 2 is turned OFF.Then, the circuit enters mode 3 . This mode is the dead time mode of Cell 2. As there is no series current, all the current on the parallel inductor flows to the diode rectifier. Shortly after that, the lower switch of Cell 2 is turned 
$\mathrm{ON}$ and the circuit becomes another resonant circuit only with capacitors of Cells 1, 3, 4, and 5 in series with Ls. As $v$ tbecomes positive in this mode, the series current starts to rise with its resonant waveform.

\section{Soft Switching}

Soft switching is a possible way of reducing losses in power electronic switches. The expression "soft switching" actually refers to the operation of power electronic switches as zero-voltage switches (ZVS) or zerocurrent switches (ZCS). The many different converter circuits that working according to these principles are generally assigned to resonance or quasi-resonance technology.

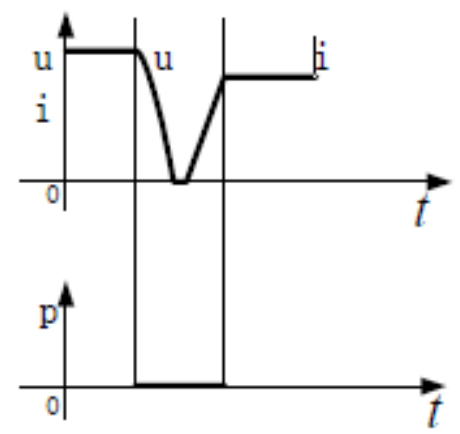

a) Turning-on

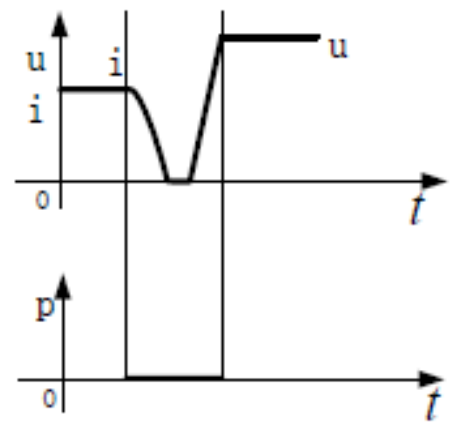

b) Turning-off

Fig. 5.Swiching of resonant converter(soft switching).

\section{Zero Voltage Switching}

- The voltage across the device is reduced to zero before the current increases or device turns ON Zero Current Switching

- The current flowing through the device is reduced to zero before the voltage increases or device turns OFF

\section{Complete Closed Loop Model Of The Proposed Scheme}

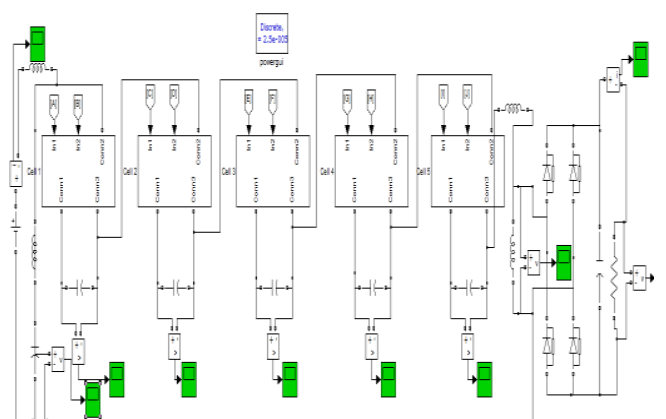

Fig. 6.Simulated Resonantconverter. 


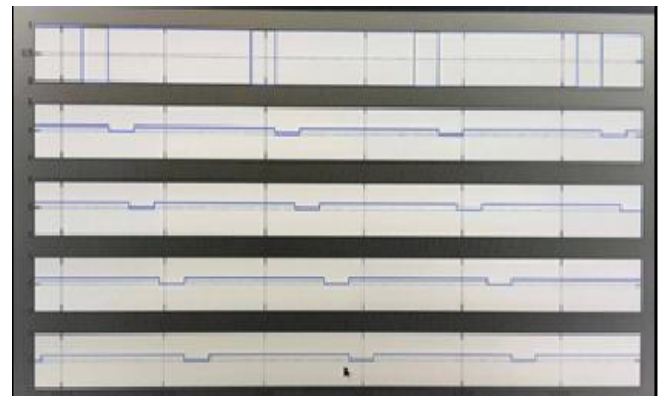

Fig. 7.Swiching Sequence of resonant converter.

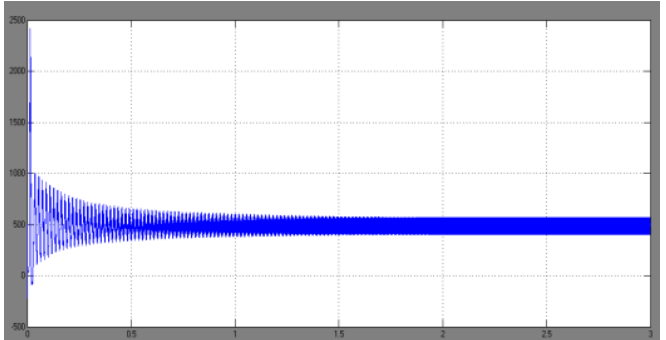

Fig. 8.Input Voltage waveform of resonant converter.

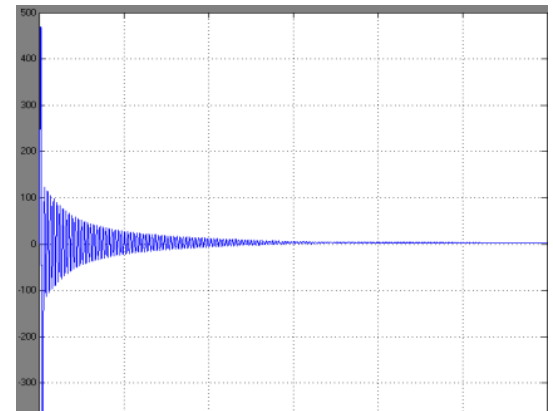

Fig. 9.Input Current waveform of resonant converter.

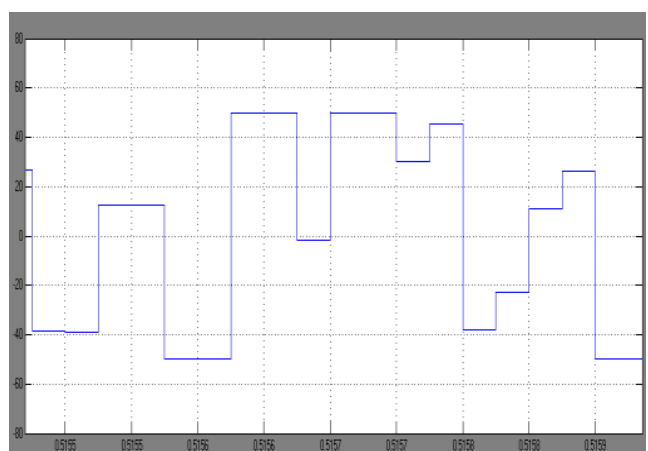

Fig. 10.Voltage Across Inductor in resonant converter.

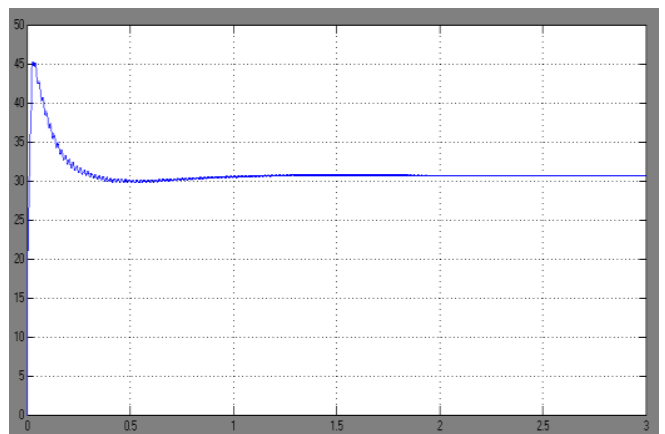

Fig. 11.Output Current of resonant converter. 


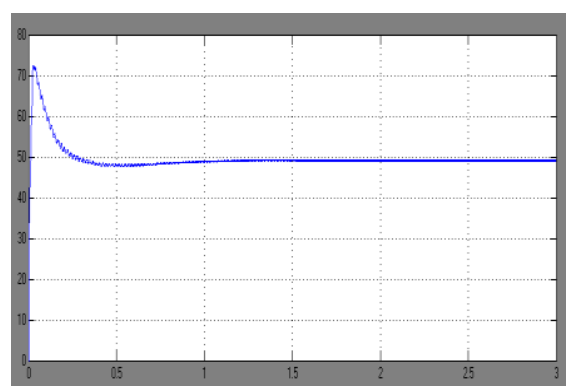

Fig. 12.Output Voltage of resonant converter.

\section{Application Of Resonant And Soft Switching Converters}

Electronic ballasts for gas-discharge lamps

- Produce high-frequency ac

Other high-frequency ac applications

- Electrosurgical generators

- Induction heaters

- Piezoelectric transformers

High-frequency high-density dc-dc converters

- Reduce switching loss and improve efficiency

High-voltage and other specialized converters

- Transformer nonidealities lead to ringing waveforms

Converters using IGBTs

- Mitigate switching loss caused by current tailing

Low-harmonic rectifiers

- Mitigate switching loss caused by diode stored charge

$\bullet$

\section{Solar Energy}

The energy of solar radiation is directly utilized in mainly two forms: i) Direct conversion into electricity that takes place in semiconductor devices called solar cells.

ii) Accumulation of heat in solar collectors.

Therefore, do not confuse solar cells with solar collectors. The directconversion of solar radiation into electricity is often described as a photovoltaic(PV) energy conversion because it is based on the photovoltaic effect. In general, the photovoltaic effect means the generation of a potential difference at the junction of two different materials in response to visible or other radiation. The whole field of solar energy conversion into electricity is therefore denoted as the "photovoltaic". Photovoltaic literally means "light-electricity", because "Photo" is a stem from the Greek word "phõs" meaning light and "Volt" is an abbreviation of Alessandro Volta's (1745-1827) name who was a pioneer in the study of electricity. Since a layman often does not know the meaning of the word photovoltaic, a popular and common term to refer to PV solar energy is solar electricity.

The oil company Shell expects that PV solar energy will become the main energy source for the "postfossil-era". Developing the PV solar energy as a clean and environmentally friendly energy source is considered at present noblemission. In this mission, the sun is consciously given an additional function tothe one that it has had: to provide energy for life on the Earth. The sun's additional function will be to provide the Earth with energy for people's comfort and well-being by producing the solar electricity. The motifs that were behind the development and application of the PV solar energy were in general the same as for all renewable energy sources. The motifs were based on the prevention of climate and environment and providing clean energy for all people. The current motifs can be divided into three categories: energy, ecology and economy.

\section{Soloar Pv Panel}

It involves the direct transformation of sunlight in to electricity energy.Photovoltaic PV Technology an inherently clean source of energy produces nonoise, smoke, acid rain water pollutants carbon dioxide or nuclear waste because it relies on the power of the sun for its fuel. At the same time, silicon the raw materials used for most PV cells is abundant and non-toxic. The large scale production of PV system has minimal impact on the environment, provided that the processes are properly controlled. Also, Since PV system are only sunlight for fuel, the environment impact of activities such as mining, exploration, production, transportation, and the hazards of coal, oil and gas are eliminated. The primary component of the photo voltaic energy system is the photovoltaic cell array. These cells consist of semiconductor material such as Silicon (si), cadmium-sulphide (cas), copper selenium arsenide (CuSeAs), gallium arsenide (GaAs). 


\begin{tabular}{|c|c|c|c|}
\hline \multirow[t]{17}{*}{ VIII. } & \multicolumn{3}{|c|}{ Parameters In Experimental Analysis } \\
\hline & Symbol & Quantity & Value \\
\hline & $P$ & Rated power & $250 \mathrm{~W}$ \\
\hline & $V_{d c}$ & Nominal input de voltage & $500 \mathrm{~V}$ \\
\hline & $v_{o}$ & Output dc voltage & $45 \mathrm{~V}$ \\
\hline & $I_{p k}$ & Maximum switch current & $30 \mathrm{~A}$ \\
\hline & $T_{b}$ & Sampling period & $1 \mathrm{~ms}$ \\
\hline & $L_{i n}$ & Input filter inductor & $9.8 \mathrm{mH}$ \\
\hline & $C_{i n}$ & Input filter capacitor & $840 \mu \mathrm{F}$ \\
\hline & $L_{s}$ & Series inductor & $6.5 \mu \mathrm{H}$ \\
\hline & $L_{p}$ & Parallel inductor & $3.3 \mathrm{mH}$ \\
\hline & $C_{1}$ & Cell 1 capacitor & $57.9 \mu \mathrm{F}$ \\
\hline & $C_{2}$ & Cell 2 capacitor & $69.1 \mu \mathrm{F}$ \\
\hline & $C_{3}$ & Cell 3 capacitor & $58.2 \mu \mathrm{F}$ \\
\hline & $C_{4}$ & Cell 4 capacitor & $57.7 \mu \mathrm{F}$ \\
\hline & $C_{5}$ & Cell 5 capacitor & $57.8 \mu \mathrm{F}$ \\
\hline & $C_{o}$ & Output capacitor & $3 \mathrm{mF}$ \\
\hline
\end{tabular}

\section{Conclusion}

Intensive literature survey has done on various maximum resonant switching and it could be used drastically to improve the efficiency of a solar PV system. Also found that ZVS is most efficient and there is an increase in the output voltage which could in utilized in various applications for future in order to save energy. This is first being implemented on a using a motor load system with its positive results it can also be further used in solar PV system. The proposed work demonstrated the state of art switched resonant converter technology. The mathematical analysis of zero voltage switching is developed. A novel method for soft switching was investigated in order to improve the efficiency of PV systems. The design and simulation of a ZVS based switched resonant converter was proposed using MATLAB. The proposed method has very good performances, fast responses with no overshoot and less fluctuation in the steady state. These controllers are able to attain an increase in the output voltage level based on the increase in the switching frequency which would drastically improve the performance of the system .

\section{References}

[1]. The paper titled 'A Half-Bridge LLC Resonant Converter Adopting Boost PWM Control Scheme for Hold-Up State Operation'. InHo Cho, Student Member, IEEE, Young-Do Kim, Student Member, IEEE, and Gun-Woo Moon, Member, IEEE. International journal of scientific and research publications, Volume :3,ISS :5,FEB 2014.

[2]. The paper titled 'A Half-Bridge LLC Resonant Converter Adopting Boost PWM Control Scheme Of Hold-Up State Operation' by In-Ho Cho, Young-Do Kim, and Gun-Woo Moon, Members, IEEE, in the IEEE transactions on power electronics, vol. 29, no. 2, February 2014.

[3]. The paper titled 'A Bidirectional-Switch-Based Wide-Input Range High-Efficiency Isolated Resonant Converter for Photovoltaic Applications' by Thomas La Bella, Wensong Yu, Jih-Sheng (Jason) Lai, Fellow, Matthew Sneaky and David Anderson, Members, IEEE, in the IEEE transactions on power electronics, vol. 29, no. 7, July 2014.

[4]. The paper titled 'A New LLC Series Resonant Converter with a Narrow Switching Frequency Variation and Reduced Conduction Losses' by Jong-Woo Kim, and Gun-Woo Moon, Members, IEEE, in the IEEE Transactions on Power Electronics, Vol. 29, No. 8, August 2014.

[5]. W. Chen, X. Ruan, and R. Zhang, -A novel zero-voltage-switching PWM full bridge converter,॥ IEEE Trans. Power Electronics., vol. 23, no. 2, pp. 793-801, Mar. 2008.

[6]. M. Borage, S. Tiwari, S. Bhardwaj, and S. Kotaiah, -A full-bridge DC-DC converter with zero-voltage-switching over the entire conversion range,\| IEEETrans.PowerElectron.,vol.23,no.4,pp.1743-1750,Mar. 2008.

[7]. This paper titled 'Analysis of a Fifth-Order Resonant Converter for High-Voltage DC Power Supplies' by NavidShafiei, MajidPahlevaninezhad, HoseinFarzanehfard, AlirezaBakhshai and Praveen Jain Fellow, Members, IEEE, in the IEEE transactions on power electronics, vol. 28, no. 1, January 2013.

[8]. This paper titled 'A Step-up Resonant Converter for Grid-Connected Renewable Energy Sources' by Wu Chen, Xiao gang Wu, Liangzhong Yao, Senior Member, IEEE, Wei Jiang and Renjie Hu, Members, IEEE, in the IEEE transactions on power electronics, vol. 30, no. 6, June 2014. 